\title{
Development of a Chromatographic Fingerprint for the Quality Control of Mallotus apelta by Using HPLC-DAD-FLD-ELSD with Malloapelta B as Marker Compound
}

\author{
Tu VA ${ }^{1}$, Cuong NX ${ }^{1}$, Thanh NV ${ }^{1}$, Dimitrov $\mathbf{V}^{2}$ and Nguyen $\mathbf{N H}^{1 *}$ \\ ${ }^{1}$ Institute of Marine Biochemistry, VAST, 18 Hoang Quoc Viet, Hanoi, Vietnam \\ ${ }^{2}$ Institute of Organic Chemistry, BG-1113 Sofia, Bulgaria
}

\begin{abstract}
High performance liquid chromatography diode array detector and Ion trap MS combined with some statistical methods was developed for the quality control of Mallotus apelta with malloapelta $B$ as marker compound. In the ESI-MS experiment, both negative and positive ESI modes were used for the detection of malloapelta $B$. All the results showed that the developed fingerprint assay was specific and could further serve for quality identification and quantitative the content of malloapelta $B$ in the Mallotus sample.
\end{abstract}

Keywords: LC-MS; Fingerprint analysis; Mallotus apelta; Malloapleta B

\section{Introduction}

The Mallotus genus, belonging to the Euphorbiaceae family, is widely distributed in Vietnam and the south of China. In Vietnam, roots, stem barks, leaves and fruits of Mallotus species have been used for hundreds of years in traditional medicine for the treatment of chronic hepatitis and enteritis [1]. In previous studies concerned the chemical components and pharmaceutical activities of Mallotus apelta, several benzopyran compounds were isolated and pharmacologically active constituents were determined [2,3]. The major components of Mallotus apelta as a series of benzopyrans such as a new chromene derivative with benzopyran skeleton was isolated and identified as 1-(5,7-dimethoxy-2,2-dimethyl-2H-chromen-8-yl)-but-2-en-1one or malloapelta $B(1)$ with high yield. Different chromatographic techniques were applied to purify several new compounds 8-(1'-oxo3'(R)-hydroxy-butyl)-5,7-dimethoxy-2,2-dimethyl-2H-1-benzopyran; 8-(acetic acid 1'-oxo-3'(R)-hydroxy-butyl ester)-5,7-dimethoxy-2,2dimethyl-2H-1-benzopyran; 6-(1'-oxo-2'-en-butyl)-5,7-dimethoxy2,2-dimethyl-2H-1-benzopyran; 6-[1'-oxo-3'(R)-hydroxy-butyl]-5,7dimethoxy-2,2-dimethyl-2H-1-benzopyran; 6-[1'-oxo-3'(R)-methoxybutyl]-5,7-dimethoxy-2,2-dimethyl-2H-1-benzopyran and 6-(1'-oxo2',3'-epoxy-butyl)-5,7-dimethoxy-2,2-dimethyl-2H-1-benzopyran from the leaves of $M$. apelta which were named as malloapelta $C, D, E$, F, G, and H, respectively [4-6], among which malloapelta $B$ is present in the greatest amounts. malloapleta $B$ with $\alpha, \beta$-unsaturated carbonyl moiety in side chain presented a potent NF-kB (Nuclear Factor-kappa $\mathrm{B}$ ), which is a major transcription factor that regulates genes responsible for both the innate and adaptive immune response, inhibitory activity $\left(\mathrm{IC}_{50}=5.0 \mu \mathrm{M}\right)$, and NFAT (Nuclear factor of activated T-cells) which is a general name applied to a family of transcription factors shown to be important in immune response, transcription factor inhibitory $\left(\mathrm{IC}_{50}=2.48 \mu \mathrm{M}\right)$ and cytotoxic activity against two human cancer cell lines (Hep-G2 and $\mathrm{KB}$ with $\mathrm{IC}_{50}=0.49 \mu \mathrm{g} / \mathrm{mL}$ and $0.54 \mu \mathrm{g} / \mathrm{mL}$, respectively) [7]. Mallotus apelta is widely distributed and used in Vietnam. The content of each component in the herb varies significantly due to difference in geographic origin, climate condition, environment and other factors. Therefore, controlling the quality of herbal medicines and their derivatives is difficult [8]. Therefore, a holistic approach for quality control is necessary. Recently, the chromatographic fingerprint technique was regarded as a useful method to control the quality of the herbal medicines and their derivatives because this technique emphasizes the systemic characterizations of compositions of samples and focuses on the identification and assessment of the stability of the components $[9,10]$. In the present study, we used high performance liquid chromatography diode array detector and Ion trap MS combined with some statistical methods to quality control of Vietnamese medicinal preparations of malloapelta $B$ as marker of Mallotus apelta sample.

\section{Experimental}

\section{Standards and materials}

All Mallotus apelta Muell.-Arg samples were authenticated by Professor Nguyen Nghia Thin (Hanoi National University, Vietnam). A voucher specimen (INPC 2847) was deposited in the herbarium of institute of Natural Products Chemistry (Hanoi, Vietnam). Malloapelta B (Figure 1) was isolated from the leaf of Mallotus apelta, this work carried out in Institute of Natural Products Chemistry, Vietnam Academy of Science and Technology. HPLC grade methanol, acetonitrile (both from Fisher Scientific, Leicestershire, UK), formic acid (Sigma-Aldrich, Steinheim, Germany), and MilliQ water (obtained

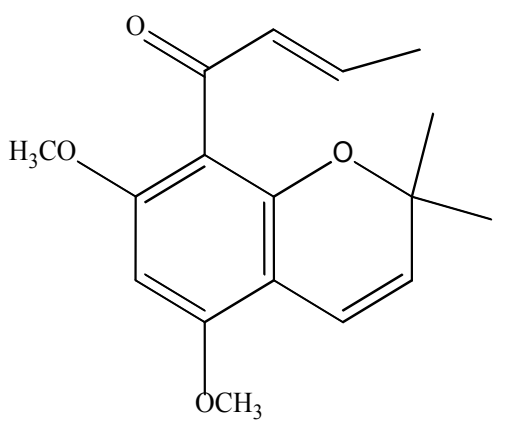

Figure 1: Structure of malloapelta B isolated from M. apelta.

${ }^{*}$ Corresponding author: Hoai Nam Nguyen, Institute of Marine Biochemistry, VAST, 18 Hoang Quoc Viet, Hanoi, Vietnam, Tel: +847917053; E-mail namnguyenhoai@imbc.vast.vn

Received June 28, 2016; Accepted July 13, 2016; Published July 18, 2016

Citation: Tu VA, Cuong NX, Thanh NV, Dimitrov V, Nguyen NH (2016) Development of a Chromatographic Fingerprint for the Quality Control of Mallotus apelta by Using HPLC-DAD-FLD-ELSD with Malloapelta $B$ as Marker Compound. Nat Prod Chem Res 4: 234. doi:10.4172/2329-6836.1000234

Copyright: (c) 2016 Tu VA, et al. This is an open-access article distributed under the terms of the Creative Commons Attribution License, which permits unrestricted use, distribution, and reproduction in any medium, provided the original author and source are credited. 
Citation: Tu VA, Cuong NX, Thanh NV, Dimitrov V, Nguyen NH (2016) Development of a Chromatographic Fingerprint for the Quality Control of Mallotus apelta by Using HPLC-DAD-FLD-ELSD with Malloapelta B as Marker Compound. Nat Prod Chem Res 4: 234. doi:10.4172/23296836.1000234

from a MilliQ water purification system, Millipore, Bedford, MA) were used to prepare the mobile phases.

\section{Instrumentation}

HPLC/MS was performed using ion trap MS instrument Agilent 1200 series (Agilent, USA) equipped with electrospray ionization (ESI) source that was connected to Agilent LC pump. This Agilent 1200 HPLC system (Agilent, USA), consisting of a vacuum degasser, quaternary pump, auto sampler and a diode array detection detector, was used. Chemstation for LC (Agilent) acquired and processed the analytical data. Helium was used as the damping and collision gas. Parent ions in ESI were examined under negative ESI (-) and positive ESI ( + ) ion modes after the direct injection of a standard solution (1 $\mu \mathrm{g} / \mathrm{mL}$ ) in $80 \%$ methanol through a syringe at a flow rate of $3 \mu \mathrm{L} / \mathrm{min}$. MS fragment analysis of malloapelta $B$ and $\mathrm{MS}^{\mathrm{n}}$ experiments were also performed. The following ESI inlet conditions were used: nitrogen was used both as the nebulising gas and as a drying gas at a temperature of $350^{\circ} \mathrm{C}$; capillary temperature was set at $285^{\circ} \mathrm{C}$; In the positive mode, the capillary voltage was set to $10 \mathrm{~V}$, the source voltage to $5 \mathrm{kV}$ and the source current to $5 \mu \mathrm{A}$; In the negative mode, the capillary voltage was set to $-4 \mathrm{~V}$, the source voltage to $4.5 \mathrm{kV}$ and the source current to $80 \mu \mathrm{A}$, a collision energy of $25 \mathrm{~V}$ was applied in both modes.

For LC/MS chromatographic separation, a Zorbax Eclipse XDB C 18 $(4.6 \times 150.0 \mathrm{~mm}, 5 \mu \mathrm{m})$ with a Zorbax Eclipse XDB $\mathrm{C}_{18}$ guard column $(4.6 \times 12.5 \mathrm{~mm}, 5 \mu \mathrm{m})$ was used at ambient temperature with a flow rate of $0.4 \mathrm{~mL} / \mathrm{min}$. The mobile phase consisted of (A) $0.1 \%$ formic acid in ACN, and (B) $0.1 \%$ formic acid in water; $5 \mu \mathrm{L}$ of sample was injected. The gradient was programmed as follows: starting at $20 \%(\mathrm{~A})$, increasing to $40 \%(\mathrm{~A})$ over $15 \mathrm{~min}$, increasing to $80 \%$ (A) over $30 \mathrm{~min}$, holding at $80 \% \mathrm{~A}$ for $10 \mathrm{~min}$, and then returning to $20 \%$ A over $5 \mathrm{~min}$. DAD detector was set at $254 \mathrm{~nm}$ for acquiring chromatograms, UV spectra and 3D-plots were recoded between 200 and $450 \mathrm{~nm}$.

\section{Preparation of samples}

To prepare the herbal extract, $2.5 \mathrm{~g}$ plant sample (leaves) was weighed and extracted three times with $25 \mathrm{~mL}$ methanol in an ultrasonic bath (Branson Ultrasonic Corporation, Connecticut, US), each time at a temperature between $40-50^{\circ} \mathrm{C}$ during 60 minutes. Then the combined extracts were filtered through a $240 \mathrm{~nm}$ pore size filter paper (Whatman, Hanoi, Vietnam) and evaporated at decreased pressure $(60 \mathrm{~Pa})$ at a temperature of $50^{\circ} \mathrm{C}$. The sample solutions were diluted 50 times. Then the solution was followed by filtration through a $25 \mathrm{~mm}$ syringe filter (VWR International, Leuven, Belgium) having a polypropylene membrane with $0.2 \mu \mathrm{m}$ pore size.

\section{Calibration curves}

To prepare malloapelta $B$ sample, a $1000 \mu \mathrm{g} / \mathrm{mL}$ standard stock solution of malloapelta $B$ was prepared and diluted to $10 \mu \mathrm{g} / \mathrm{mL}$ to provide the working solution. Then this solution was used to prepare a series of standards having concentrations of $1 \mu \mathrm{g} / \mathrm{mL}, 0.8 \mu \mathrm{g} / \mathrm{mL}, 0.5 \mu \mathrm{g}$ $/ \mathrm{mL}, 0.25 \mu \mathrm{g} / \mathrm{mL}, 0.1 \mu \mathrm{g} / \mathrm{mL}, 0.05 \mu \mathrm{g} / \mathrm{mL}, 0.025 \mu \mathrm{g} / \mathrm{mL}$ in pure $80 \%$ methanol solution and also in the extract from Mallotus apelta to allow calibration of the sample. A calibration curve was obtained by plotting the ratio of the peak areas of the analyte (Figure 2).

\section{Results and Discussion}

\section{Selection of suitable chromatographic conditions}

In the course of optimizing the conditions of separation, the influence of the stationary and mobile phases were firstly investigated.
Considering the presence of benzopyrans in the herbal extraction, a little amount of formic acid was added to the mobile phase to reduce the ionization of these compounds. Different elution conditions with methanol-water, acetonitrile-water and different concentrations of formic acid in water and in organic mobile phase were compared to get the most suitable mobile phase. The results showed that best resolution and shortest analysis time were achieved when the $0.1 \%$ formic acid in ACN, and $0.1 \%$ formic acid in water system was used as mobile phase. As seen in Figure 3a, not all of the peaks but most of the main peaks include peak's malloapeta B could be well separated by the optimum gradient elution. It is not necessary to strive for baseline separation of all components in one run, to fulfill the identification of objectives of fingerprint of herbal medicines. So the resolution of the chromatograms of Mallotus apelta sample under the optimized conditions was acceptable.

Two columns (Zorbax Sil $C_{18}$ column with $2.5 \times 250 \mathrm{~mm}$ i.d. $5 \mu \mathrm{m}$; Zorbax Eclipse XDB C ${ }_{18}$ column with $4.6 \times 150.0 \mathrm{~mm}$ i.d., $5 \mu \mathrm{m}$ ) were screened. The best selectivity and resolution can be observed on the Zorbax Eclipse XDB C ${ }_{18}(5 \mu \mathrm{m} ; 4.6 \times 150.0 \mathrm{~mm}$ I.D. $)$ column as shown in Figure 3a. Over 18 sharp and symmetrical peaks were obtained. Column temperature was an important parameter influencing retention, selectivity, system pressure and column stability. The column temperature at 15,25 and $35^{\circ} \mathrm{C}$ also were investigated and the results indicated that $35^{\circ} \mathrm{C}$ was the optimum temperature. Selection of detection wavelength was one of the key factors contributing to a reliable and reproducible HPLC fingerprint of Mallotus apelta. Diode array detector (DAD) was applied to select the optimum wavelength. From the 3D-plots, it was observed that the UV absorption maximum for the malloapelta $B$ was at $254 \mathrm{~nm}$ (Figure 3b). Hence, $254 \mathrm{~nm}$ was selected as the detection wavelength.

\section{Validation of the quantitative analysis}

As shown in Figure 2, the calibration curve showed good linear regression $\left(\mathrm{R}^{2}>0.9991\right)$ and the limit of detection (LOD) was less than $0.025 \mu \mathrm{g} / \mathrm{mL}$ per injection, indicating that this method is precise and sensitive for the quantitative evaluation of malloapleta B in Mallotus apelta sample. The current method was also utilized to analyze the quantitative of malloapelta $B$ in Mallotus apelta sample collected in Tamdao province. In this sample, content of malloapelta $B$ was found to be $0.2 \%$, while other samples collected in other provinces were found to be lower than that in Tamdao province (Table 1).

\section{General characters and analysis MS data of the main peaks}

MS spectra was recorded after the direct injection of malloapelta $B$, malloapelta $B$ exhibited its most intense adduct ions under ESI positive mode; it appeared at $\mathrm{m} / \mathrm{z} 289[\mathrm{M}+\mathrm{H}]^{+}$(Figure 4). malloapelta $B$ do not exhibite its most intense adduct ions under ESI negative mode.

LC-MS was adopted to identify the present of malloapelta $B$ in the chemical constituents of M. apelta. ESI in both negative and positive

\begin{tabular}{|c|c|c|c|c|}
\hline $\begin{array}{c}\text { Sample } \\
\text { number }\end{array}$ & Species & $\begin{array}{c}\text { Collection } \\
\text { time }\end{array}$ & Origin & $\begin{array}{c}\text { (\%) } \\
\text { malloapelta B }\end{array}$ \\
\hline 1 & Mallotus apelta & August, 2009 & VanBan-Laocai & 0.18 \\
\hline 2 & Mallotus apelta & $\begin{array}{c}\text { November, } \\
2009\end{array}$ & $\begin{array}{c}\text { TamDao- } \\
\text { Vinhphuc }\end{array}$ & 0.20 \\
\hline 3 & Mallotus apelta & $\begin{array}{c}\text { November, } \\
2009\end{array}$ & $\begin{array}{c}\text { Dongdang- } \\
\text { Langson }\end{array}$ & 0.172 \\
\hline 4 & Mallotus apelta & $\begin{array}{c}\text { December, } \\
2009\end{array}$ & $\begin{array}{c}\text { Hamyen- } \\
\text { Tuyenquang }\end{array}$ & 0.156 \\
\hline 5 & Mallotus apelta & June, 2010 & Paco-Hoabinh & 0.19 \\
\hline
\end{tabular}

Table 1: Mallotus apelta samples with indication of collection time, origin and percent of malloapelta B. 
Citation: Tu VA, Cuong NX, Thanh NV, Dimitrov V, Nguyen NH (2016) Development of a Chromatographic Fingerprint for the Quality Control of Mallotus apelta by Using HPLC-DAD-FLD-ELSD with Malloapelta B as Marker Compound. Nat Prod Chem Res 4: 234. doi:10.4172/23296836.1000234

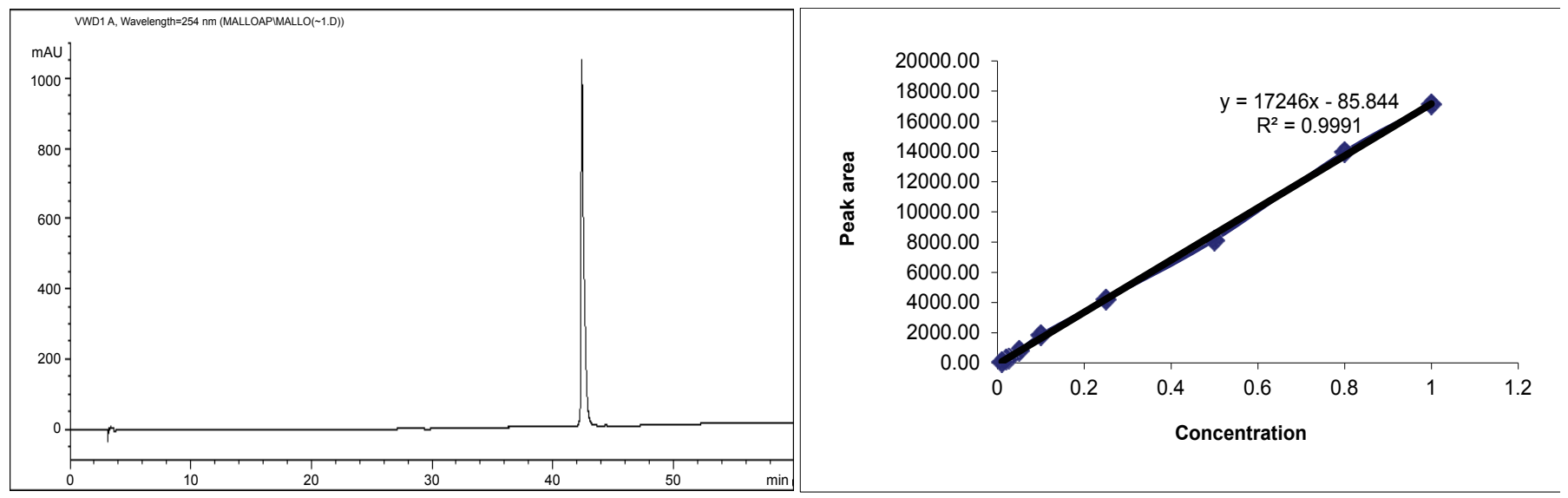

Figure 2: Calibration curves and chromatogram of malloapelta B.
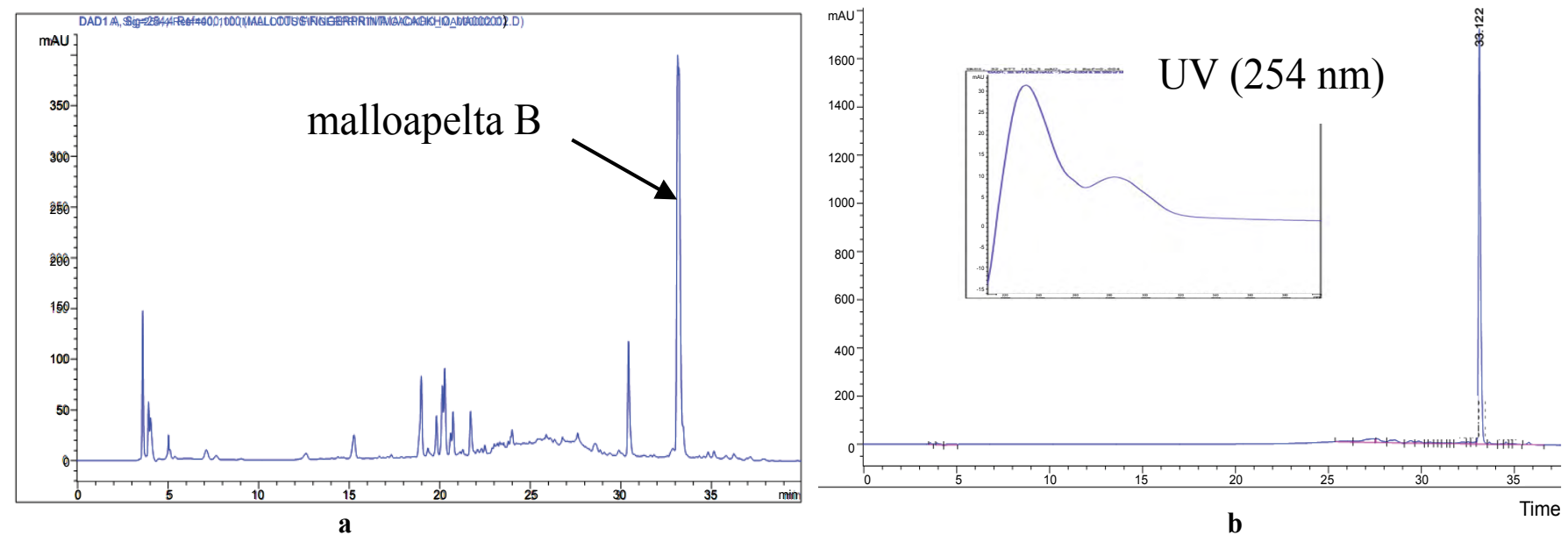

Figure 3: a) Chromatograms of Mallotus apelta sample and b) malloapelta B sample with Zorbax Eclipse XDB $\mathrm{C}_{18}(5 \mu \mathrm{m} ; 4.6 \times 150.0 \mathrm{~mm}$ I.D.) column.

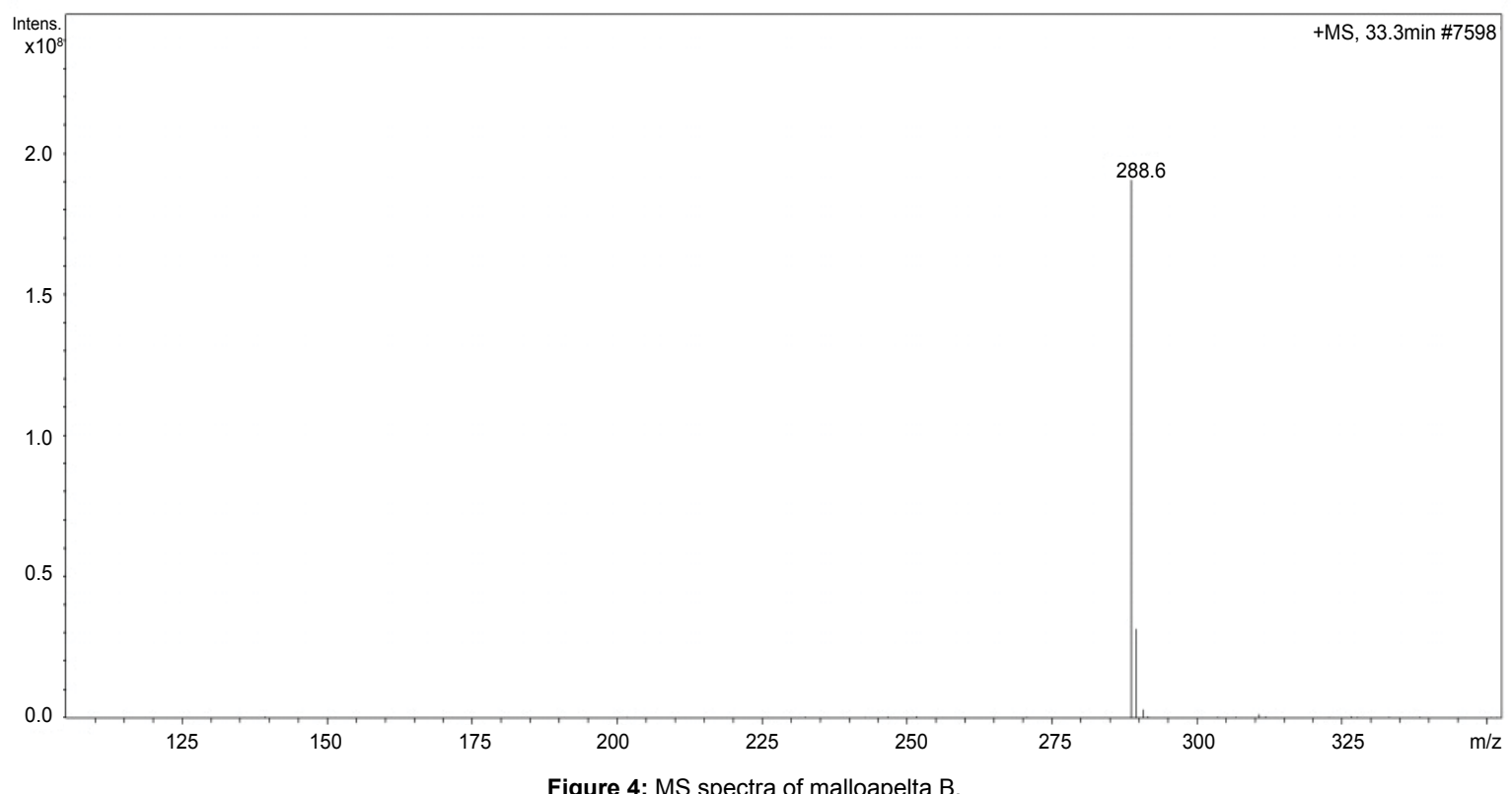

Figure 4: MS spectra of malloapelta B. 
Citation: Tu VA, Cuong NX, Thanh NV, Dimitrov V, Nguyen NH (2016) Development of a Chromatographic Fingerprint for the Quality Control of Mallotus apelta by Using HPLC-DAD-FLD-ELSD with Malloapelta B as Marker Compound. Nat Prod Chem Res 4: 234. doi:10.4172/23296836.1000234

modes was used for the detection of malloapelta B. Positive mode ESI was found to be sensitive for malloapleta B. In the ESI-MS experiment, the molecular weight of malloaplta B was obtained (Figure 4). Then on the basic of the comparison of UV spectrum, HPLC retention time and mass spectra with the reference above. We tentatively identified and deduced the malloapelta $B$ in the Mallotus apelta samples.

\section{Acknowledgements}

This study was financially supported by a Grant from Vietnam Academy of Science and Technology (Codes: VAST.HTQT.Belar.05/15-16).

\section{References}

1. Loi DT (2001) Glossary of Vietnamese Medicinal Plants. Science \& Technics Publication, Hanoi, Vietnam.

2. An TY, Hu LH, Cheng XF, Chen ZL (2001) Benzopyran derivatives from Mallotus apelta. Phytochemistry 57: 273-278.

3. Kiem PV, Dang NH, Bao HV, Huong HT, Minh CV, et al. (2005) New cytotoxic benzopyrans from the leaves of Mallotus apelta. Archives of Pharmacal Research 28: 1131-1134.
4. Kiem PV, Minh CV, Huong HT, Nguyen HN, Lee JJ, et al. (2004) Pentacyclic triterpenoids from Mallotus apelta. Archives of Pharmacal Research 27: 1109-1113.

5. Minh CV, Kiem PV, Nguyen HN, Huong HT, Lee JJ, et al. (2005) Chemical Investigation and biological studies of Mallotus apelta. IV. Constituents with inhibitory activity against NFAT and NF-kB activation from Mallotus apelta. Vietnamese Journal of Chemistry 43: 773-777.

6. Nguyen HN, Dang NH, Kiem PV, Chinh LV, Binh PT, et al. (2007) Study on benzopyrans and other isolated compounds from Mallotus apelta. Vietnamese Journal of Chemistry 45: 111-121.

7. Kiem PV, Dang NH, Bao HV, Huong HT, Minh CV, et al. (2005) New cytotoxic benzopyrans from the leaves ofMallotus apelta. Arch Pharm Res 28: 1131-1134.

8. Kiem PV, Minh CV, Huong HT, Nguyen HN, Lee JJ, et al. (2005) Chemica Investigation and biological studies of Mallotus apelta, III- New chromene derivative from Mallotus apelta. Vietnamese Journal of Chemistry 43: 652-656.

9. Mahady GB, Fong HHS, Farnsworth NR (2001) Botanical Dietary Supplements: Quality, Safety and Efficacy. Swets and Zeitlinger Publishers, The Netherlands.

10. Liang YZ, Xie P, Chan K (2004) Quality control of herbal medicines. J Chromatogr B Analyt Technol Biomed Life Sci 812: 53-70. 